\title{
MERCOSUL E DIREITOS HUMANOS NO QUADRO DO CONFLITO ENTRE A CONSTITUIÇÃO BRASILEIRA E OS TRATADOS INTERNACIONAIS
}

\author{
Ana Paula Barbosa-Fohrmann * \\ Instituto Max-Planck de Direito Público Comparado \\ e de Direito Internacional Público - Alemanha \\ abarbosa@mpil.de/ap_cbarbosa@yahoo.de
}

\section{INTRODUÇÃO}

A proposta deste estudo é apresentar um panorama doutrinário e jurisprudencial do conflito de fontes no Brasil, particularmente, o conflito existente entre a Constituição Brasileira de 1988 e os tratados internacionais.

Nesse quadro, vai-se proceder a uma descrição do debate entre as duas principais escolas teóricas - dualista e monista- e analisar a aplicação de suas teses ao Direito da Integração Regional, MERCOSUL, e aos direitos humanos.

Por fim, pretende-se investigar se o atual debate doutrinário e jurisprudencial está pronto para responder à crescente necessidade de flexibilização e de concreção que exigem o MERCOSUL e os direitos humanos ou se realmente há necessidade de revisão ou emenda de princípios e normas constitucionais, sobretudo, no contexto do processo de integração do MERCOSUL.

\section{UM PANORAMA DO CONFLITO DE FONTES}

\section{Lei Interna e Tratado Internacional}

\subsection{A Posição da Doutrina}

Pode ocorrer conflito entre uma lei interna de um determinado Estado e um tratado ou convenção ratificado por ele. Tal embate se manifesta quando a lei indica uma solução para certo conflito e um tratado ou convenção indica uma outra.

\footnotetext{
* Pós-Doutora e Doutora em Direito pela Ruprecht-Karls-Universität Heidelberg. Mestre em Direito Público e Bacharel em Direito pela Universidade do Estado do Rio de Janeiro (UERJ). Atualmente, é Pesquisadora e Editora Jurídica da Enciclopédia de Direito Internacional Público do Instituto Max-Planck de Direito Público Comparado e de Direito Internacional Público em Heidelberg, Alemanha.
} 
Para a sua solução, recordemos o debate entre as escolas dualista e monista. Para os dualistas Dionisio Anzilotti e Carl Heinrich Triepel, o Direito Interno e o Direito Internacional se comportam como esferas jurídicas distintas, ou seja, como duas esferas que não se superpõem (ANZILOTTI, 1955, pp. 49 s.; Triepel, 1899, pp. 169 s.).

Sobre essa escola, comenta Celso D. de Albuquerque Mello: "Esta concepção conduz à denominada 'teoria da incorporação', isto é, para que uma norma internacional seja aplicada no âmbito interno do Estado é preciso que este faça primeiro a sua 'transformação' em direito interno, incorporando-a ao seu sistema jurídico. É isto uma conseqüência da completa independência entre as duas ordens jurídicas, o que significa dizer também que não existe uma possibilidade de conflitos entre elas" (Mello, 1986, p. 75).

A segunda escola teórica, cujo mais importante defensor foi Hans Kelsen, sustenta não ser possível haver dois sistemas jurídicos distintos. O Direito Internacional e o Direito Interno são convergentes, superpõem-se e formam uma ordem jurídica única (Kelsen, 1953, pp. 184 s.; Errázuriz MackenNa, 1986, p. 321).

O monismo se subdivide em três correntes: 1 - a que defende a primazia do Direito Interno sobre o Internacional; 2 - a que defende a primazia do Direito Internacional sobre o Interno; 3 - e a que os equipara, dependendo a prevalência de uma fonte sobre a outra da ordem cronológica de sua criação. Tal é o monismo moderado.

No Brasil, a maioria da doutrina, como Haroldo Valladão (VAlladÃo, 1974, p. 53), Oscar Tenório (Tenório, 1976, pp. 93 s.) e Celso D. de Albuquerque Mello (Mello, 2000, pp. 365-367), é partidária do monismo com superioridade do Direito Internacional sobre o Direito Interno; já a minoria, como Amílcar de Castro (CASTRO, 1956, pp. 131 s.), é adepta do dualismo. E há aqueles ainda que adotam as duas posiçóes, como Flávia Piovesan, que, embora defenda o monismo para a incorporação de tratados internacionais de direitos humanos, segue, contudo, a linha dualista para a incorporação dos demais tipos de tratados no sistema jurídico pátrio (PIOVESAN, 1996, p. 111).

\subsection{A Posição do Supremo Tribunal Federal}

Até 1977, o posicionamento do Supremo Tribunal Federal (STF) era no sentido do monismo com primazia do Direito Internacional sobre o Interno. A partir de 1977, com a decisão do Recurso Extraordinário n 80.004, o STF passou a adotar o monismo moderado e o denominado "sistema paritário", segundo o qual tratado e lei interna gozam do mesmo status de lei ordinária. O então recurso extraordinário interposto junto ao STF envolveu a Lei Uniforme de Genebra sobre Letras 
de Câmbio e Notas Promissórias, que entrou em vigor com o Decreto 57.663, de 1966, e uma lei posterior, o Decreto-lei 427/69. O conflito relacionou-se com a obrigatoriedade ou não de existência do aval aposto na nota promissória - uma exigência formal para a validade do título que não constava no texto internacional. Prevaleceu, pois, o Decreto 427/69.

João Grandino Rodas comenta os votos dos Ministros do STF: "Os Ministros Xavier de Albuquerque, relator, e Eloy da Rocha, na esteira dos precedentes (...), secundaram a tradicional teoria do primado do Direito Internacional. Os Ministros que compuseram a maioria, não obstante, fundamentaram-se na ausência de 'status' hierárquico superior para o tratado internacional na então vigente Constituição, o que redundaria em valorizar a norma mais recente" (RODAS, 1992, pp. 322 s.).

\section{Constituição e Tratado Internacional}

\subsection{Visão Normativa e Predominante}

Para Luís Roberto Barroso, o conflito que pode haver entre Constituição e tratado pode ser solucionado, atendendo a um duplo aspecto: o da constitucionalidade extrínseca e o da constitucionalidade intrínseca (BARROSO, 2003, pp. 21 s.).

A primeira hipótese, a da constitucionalidade extrínseca, diz respeito à violação do tratado aprovado de regras constitucionais de competência e de procedimento para a sua celebração, aprovação parlamentar, ratificação e entrada em vigor (arts. 49, I e 84, VIII da CF/88). Acentua Barroso que os defensores do monismo só admitem essa possibilidade de inconstitucionalidade do tratado, ou seja, rejeitam qualquer verificação intrínseca, material ou de conteúdo do texto do tratado em face da Constituição (BArroso, 2003, p. 22). Entre os seus defensores, inclui-se Haroldo Valladão, para quem o tratado só pode ser revogado, por uma das partes, através da denúncia, desde que ele já se encontre em vigor no momento da promulgação da Constituição. Porém, se for celebrado na vigência de uma determinada Carta e for com essa incompatível, prevalece a norma constitucional (VALLADÃo, 1974, p. 94).

$\mathrm{Na}$ segunda hipótese, a da constitucionalidade intrínseca, o Brasil vem admitindo sua verificação desde a Constituição de 1891. Atualmente, a regra é a do art. 102, III, "b" da CF/88, a qual dispóe acerca do cabimento de recurso extraordinário quando a decisão recorrida declarar a inconstitucionalidade de tratado ou de lei federal.

Ressalta Barroso que, ao prever a declaração de inconstitucionalidade de tratado, o Texto Constitucional só pode estar se referindo ao que seja posterior à Constituição, pois não se declara a inconstitucionalidade de preceito anterior à Carta (BARroso, 2003, p. 30). Essa é a regra do Direito Constitucional intertemporal brasileiro. 
À vista do entendimento do STF, o conflito entre a Constituição e tratados se soluciona por meio do Princípio da Supremacia da Constituição sobre os atos internacionais convencionais, ou seja, o tratado anterior não sobrevive, se for contrário à nova Carta. A questão constitucional sobreveio relativamente à cobrança do imposto sobre circulação de mercadorias (ICM) na importação de bens de capital de países membros do Acordo Geral de Tarifas e Comércio (General Agreement on Tariffs and Trade, GATT). No julgamento do Recurso Extraordinário $\mathrm{n}^{\circ}$ 109.173-SP, a Corte Constitucional foi clara: "Inadmissível a prevalência de tratados e convenções internacionais contra o texto expresso da Lei Magna (...) Os acordos internacionais, como é o caso do GATT protegem os produtos originários dos países contratantes. Todavia, não há como admitir, como deixou entender a decisão recorrida, que na nova tributação autorizada pela Emenda Constitucional n. 23, deva ser atendido o que prescreve um tratado internacional (...) Hierarquicamente, tratado e lei situam-se abaixo da Constituição Federal. Consagrar-se que um tratado deve ser respeitado, mesmo que colida com o texto constitucional, é imprimir-lhe situação superior à própria Carta Política" (Revista Trimestral de Jurisprudência, 1987, $\mathrm{N}^{\circ} 121$, p. 270).

Diante de tudo isso, Barroso conclui "...O tratado celebrado na vigência de uma Constituição e que seja com ela incompatível, do ponto de vista formal (extrínseco) ou material (intrínseco), é inválido e sujeita-se à declaração de inconstitucionalidade incidenter tantum, por qualquer órgão judicial competente, sendo tal decisão passível de revisão pelo Supremo Tribunal Federal, em sede de recurso extraordinário. $\mathrm{O}$ tratado que se encontrar em vigor quando do advento de um novo texto constitucional, seja este fruto do poder constituinte originário ou derivado, será tido como ineficaz, se for com ele incompatível" (BARROso, 2003, p. 32).

\subsection{Visão Moral e Alternativa}

De acordo com o argentino Carlos Santiago Nino, é possível tratar o conflito entre a Constituição e o tratado com base numa visão valorativa e de princípios morais.

Para Nino, a Constituição histórica, seja essa uma descrição da prática social atual, seja uma prescrição da prática social futura, não é importante do ponto de vista lógico para determinar a validade de outras normas do sistema jurídico (NINO, 1997, p. 30).

Para comprovar tal posição, Nino examina uma questão de conflito entre o Direito Interno e o Internacional. O autor recorda: “...en Argentina, hay un debate referido a la autoridad de la Corte Interamericana de Derechos Humanos, estable- 
cida por la Convención Interamericana de Derechos Humanos. De acuerdo con la Convención, se supone que la autoridad de la Corte prevalece sobre los jueces nacionales en los países que, como Argentina, han ratificado en forma completa la Convención. Este reconocimiento de autoridad está, sin embargo, en conflicto con el artículo 100 de la Constitución Argentina, que establece que el Poder Judicial es ejercido por la Corte Suprema y los tribunales inferiores, implicando fuertemente que no puede existir ningún tribunal de mayor jeraquía que la Corte suprema" (NINO, 1997, p. 42).

Com base nesse aparente conflito entre o sistema jurídico nacional e o internacional, ele diferencia as posições já aqui examinadas. Recordemos: $\mathrm{O}$ monismo nacional afirma que a validade do Direito Internacional depende de sua compatibilidade com a ordem legal nacional. $\mathrm{O}$ monismo internacional estabelece exatamente o oposto, ou seja, os sistemas legais nacionais derivam sua validade do Direito Internacional, e o dualismo sustenta que cada sistema é válido independentemente do outro.

No caso argentino, aqueles que afirmam a superioridade do Direito Interno sobre os tratados se baseiam no artigo 27 da Constituição, o qual estabelece que os tratados devem estar em conformidade com os princípios constitucionais de Direito Público. Aqueles que são a favor da prevalência dos atos internacionais fundam sua defesa nos artigos 27 e 46 da Convenção de Viena de 1969. Essa Convenção proíbe os Estados-Partes de invocarem o Direito Interno para justificar seu comportamento internacional, a menos que o conflito entre o tratado e o Direito Interno indique uma ausência de consentimento ao documento estrangeiro ou o próprio documento estipule que a regra interna tenha preponderância.

Aqueles que, portanto, conferem prioridade à Constituição nacional em detrimento dos tratados fundamentam sua defesa no artigo 27 da Constituição argentina. Isso porque pressupõem a prevalência da Carta sobre a Convenção de Viena. Pode-se proceder ao mesmo raciocínio de forma inversa. Os que defendem os tratados internacionais, baseando seus argumentos nos artigos 27 e $46 \mathrm{da}$ Convenção de Viena, pressupõem a supremacia do tratado sobre a Constituição, pois consideram que a Convenção tem maior poder de resolução.

Nino apresenta, contudo, críticas a essa forma de compreensão do conflito de fontes: "Las reglas que sostienen su propria validez y prevalencia sobre otras reglas son absolutamente vacías, desde que ellas son autorreferentes" (NINO, 1997, p. 43). E continua: "Cada vez que se decide aplicar una norma constitucional por sobre un tratado, o cuando se decide, por el contrario, aplicar un tratado por sobre una constitución, se hace sobre la base de consideraciones externas a la constitución o al tratado en cuestión. No podemos apoyarnos en la constitución o el tratado para establecer su propria validez. En otras palabras, la Constitución puede asignar 
validez a otras reglas sólo si ella misma es válida, pero ésta no puede ser la base de su propria validez. Su validez está necessariamente basada en principios básicos $\mathrm{u}$ otros fundamentos supraconstitucionales. Este argumento se aplica también a cualquier otra regla" (NINO, 1997, pp. 43 s.).

Assim, em Nino, quando a Constituição não puder conceder validade a outras regras, se ela mesma não for válida, ou quando não puder conceder validade a si mesma, não poderá outorgar validade a outras regras.

Para que possa desempenhar tal papel -o de atribuir validade a outras regras do sistema jurídico-, deve recorrer a considerações externas à prática constitucional, ou seja, a consideraçõos de caráter moral. Somente princípios que tenham esse caráter podem justificar determinadas práticas sociais, como é o caso da interpretação e aplicabilidade de normas constitucionais ou de outras normas que respaldam a sua validade na Constituição.

É nesse sentido que a concepção de supremacia do tratado sobre a Constituição ou vice-versa ou, ainda, a de ambos constituírem dois campos que não se superpõem só se justifica com base em princípios morais que tanto estão além da Constituição e que, por meio dela, se tornam jurídicos quanto pelos tratados. Não há como teoricamente fundamentar algum conceito ou proposição puramente com suporte em si mesmo, pois recairíamos numa tautologia. Talvez, seja esse o maior equívoco dos que defendem a linha de argumentação de justificação do Direito por meio do próprio Direito.

\section{O Direito Constitucional e a sua RelaÇão com o Direito da INTEGRAÇÃo E os Direitos Humanos}

\section{Direito da Integração: O MERCOSUL}

Quanto ao processo de integração impulsionado pela iniciativa do Mercado Comum do Sul (MERCOSUL), é importante que se relembre, primeiramente, o histórico desse Mercado para depois analisar como esse tema foi tratado pelo ordenamento constitucional brasileiro e, por fim, tecer algumas críticas à atual Carta.

Os primórdios do processo de integração econômica remontam à Ata de Integração Brasil-Argentina de 1986, cujo objetivo, na realidade, foi mais político que econômico. Com efeito, esse documento visou a uma distensão nas relações bilaterais, visto que o ambiente político já se mostrava, de certa forma, propício: o governo Alfonsín, eleito democraticamente, estava no poder desde 1983 e, no Brasil, nos encontrávamos no fim de um longo período ditatorial. Note-se, portanto, que o Processo de Integração e Cooperação Econômica, previsto pela Ata, postulou, em primeiro lugar, o fim do discurso beligerante. A partir daí, houve 
uma paulatina aproximação e abertura do diálogo entre os dois países: a Argentina, já sob o regime democrático, e o Brasil, em vias de tornar-se.

Em 1988, assinaram ambos os países o Tratado de Integração, Cooperação e Desenvolvimento, com o objetivo de constituir um espaço econômico comum no prazo de dez anos. Em 1990, firmaram a Ata de Buenos Aires que reduziu pela metade o prazo do Tratado de 1988, de tal forma que, acelerando o processo, pretenderam modernizar suas economias, tornando-as complementares, e, com isso, buscar uma inserção mais competitiva no mercado internacional.

Em 1991, firmaram o Tratado de Assunção, o qual previu um prazo de transição até o fim de 1994 para a constituição e configuração definitiva do MERCOSUL.

Ademais, assinale-se que, entre os objetivos do Mercado, ao qual, em 1991, também aderiram Paraguai e Uruguai, estão a livre circulação dos fatores de produção -bens, serviços e pessoas-, a extinção das barreiras tarifárias e não-tarifárias na zona de livre comércio (tarifa intrazona: zero) e, com relação a terceiros mercados, o estabelecimento de uma tarifa externa comum (tarifa extrazona: igual) e de uma coordenação das políticas macroeconômicas. Pode-se dizer; portanto, que o MERCOSUL passou de uma zona de livre comércio para uma união aduaneira (tarifa externa comum + livre circulação de bens), com o fito de se tornar um mercado comum (livre circulação de todos os fatores de produção).

Em suma, o termo "MERCOSUL" ainda não se traduziu, na prática, em um mercado comunitário. Tal é o propósito dos Estados-Partes. Não se trata de um mercado comum porque não possui órgãos supranacionais, como a Comissão e a Corte de Justiça que existem na Comunidade Européia (CE).

\section{A Questão do Conflito de Fontes no MERCOSUL}

Sobre a relação entre o Direito da Integração e o Direito Constitucional, Mello segue a mesma linha defendida por Paulo Borba Casella, qual seja, a do monismo com superioridade do tratado internacional sobre a lei interna. Isso implica afirmar que aquele não se sujeita à alteração ou revogação por lei ordinária posterior (Mello, 1999, p. 22). Tal forma de examinar o tema, segundo ambos os autores, impóe-se como um imperativo jurídico sob pena de o processo de integração ser esvaziado.

É importante ressaltar ainda que Mello atesta o fato de que não existe no ordenamento constitucional -diferentemente das Constituiçõos dos parceiros do Brasil no MERCOSUL- dispositivo que regulamente as relações entre normas estrangeiras e as nacionais, salvo o parágrafo $2^{\circ}$ do artigo $5^{\circ}$ da Carta de 1988 , que incorpora ao Direito pátrio tão-somente os direitos humanos consagrados em tratados que tenham sido ratificados. A previsão dispõe: "Os direitos e garantias 
expressos nesta Constituição não excluem outros decorrentes do regime e dos princípios por ela adotados, ou dos tratados internacionais em que a República Federativa do Brasil seja parte".

Pode-se extrair daí que a matéria "integração" ficou de fora de tal previsão porque parece claro que não deveria vir elencada no Título II referente a direitos e garantias fundamentais e também porque, de certa forma, o artigo $4^{\circ}$ sobre princípios que regem o País em suas relações internacionais e, mais precisamente, o parágrafo único desse dispositivo dedicam-se a tratar do tema no quadro latino-americano. De acordo com a disposição: "A República Federativa do Brasil rege-se nas suas relações internacionais pelos seguintes princípios: I- independência nacional; II- prevalência dos direitos humanos; III- autodeterminação dos povos; IV- não-intervenção; V- igualdade entre os Estados; VI- defesa da paz; VII- solução pacífica dos conflitos; VIII- repúdio ao terrorismo e ao racismo; IX- cooperação entre os povos para o progresso da humanidade; $\mathrm{X}$ - concessão de asilo político". Parágrafo único: "A República Federativa do Brasil buscará a integração econômica, política, social e cultural dos povos da América Latina, visando à formação de uma comunidade latino-americana de nações".

Na opinião de Casella, o MERCOSUL só se concretizará efetivamente quando houver uma revisão da Carta de 1988, senão tenderá ao fracasso. Com suporte em uma visão essencialmente crítica, propõe: “....alterar a redação dos dispositivos relativos à soberania e independência nacional, coordenando a expressão destes ao princípio geral colocado pelo parágrafo único do art. $4^{\circ}$; alterar a divisão de competências legislativas e dos tribunais, inserindo o tribunal supranacional dentre os integrantes do sistema judiciário, resguardando sua esfera de competência na interpretação e aplicação das normas comuns (arts. 92 e 101 e seguintes da Constituição); resguardar a esfera de competência legislativa e administrativa dos órgãos comuns ou comunitários, alterando-se as competências privativas da União (especialmente os arts. 21 a 24, bem como os dispositivos pertinentes dos títulos VI e VII, relativos, respectivamente, à Tributação e o Orçamento, bem como a Ordem econômica e social, arts. 145 a 179 e 180 a 192 da Constituição)" (CAsella, 1994, p. 98).

É nesse sentido que Casella se mostra a favor da superposição dos tratados internacionais sobre o Direito Interno. Em outras palavras, os tratados não devem estar sujeitos à lei interna posterior sob pena de esvaziamento de seu conteúdo. Mas esclarece que nem a jurisprudência, nem a legislação interna tem observado a extensão que pode ser atribuída ao art. $5^{\circ}$, parágrafo $2^{\circ}$ da Constituição de 1988 , em relação ao qual se poderia construir toda uma interpretação que zelasse pela estrita observância dos tratados. A conduta de tribunais e do Legislativo podem gerar, pela sua inobservância, resultados gravosos. 


\section{Os Direitos Humanos}

Pelo fato de o artigo $5^{\circ}$, parágrafo $2^{\circ}$ da Lei Maior constituir uma cláusula constitucional aberta, ou seja, que alarga também o bloco de constitucionalidade para princípios não-escritos, a Carta de 1988 não exclui outros direitos e garantias fundamentais que advenham de tratados. Com base em tais premissas, defende Flávia Piovesan uma nova classificação dos direitos previstos pela Constituição: "a) a dos direitos expressos na Constituição (por exemplo, os direitos elencados pelo texto nos incisos I a LXXVII do art. $5^{\circ}$ ); b) a dos direitos expressos em tratados internacionais de que o Brasil seja parte; c) a dos direitos implícitos (direitos que estão subentendidos nas regras de garantias, bem como os direitos decorrentes do regime e dos princípios adotados pela Constituição)" (PIOVESAn, 1996, p. 89).

Sobre o conflito de fontes, argumenta que a teoria da paridade não se aplica aos tratados internacionais de direitos humanos, tendo em vista que a Carta de 1988 lhes assegura privilégio hierárquico e lhes confere natureza de norma constitucional. Esse tratamento diferenciado e atribuído pelo artigo $5^{\circ}$, parágrafo $2^{\circ}$ da Constituição justifica-se, na medida em que os atos internacionais de direitos humanos apresentam um traço especial que os leva a se diferenciar dos tratados internacionais comuns. Isso quer dizer que, enquanto estes últimos buscam o equilíbrio e a reciprocidade de relações entre Estados-Partes, aqueles transcendem os meros compromissos entre os Estados pactuantes. Em outras palavras, os tratados de direitos humanos objetivam salvaguardar os direitos do ser humano e, não, as prerrogativas dos Estados.

Portanto, em matéria de tratados internacionais de direitos humanos, a Constituição Federal de 1988 acolheu a sistemática da incorporação automática dos tratados e adota, dessa forma, a concepção monista, ou seja, basta a ratificação do tratado e automaticamente dá-se a sua vigência interna. O mesmo regime, porém, não pode ser aplicável aos demais tratados que, na visão de Piovesan, obedecem à sistemática da incorporação não automática, o que implica afirmar que o sistema jurídico brasileiro segue o regime dualista para os tratados tradicionais (PIOVESAN, 1996, p. 111).

Quanto ao impacto dos atos internacionais de direitos humanos no ordenamento interno, ressalta Piovesan que, em caso de conflito entre a Constituição e tais atos, deve-se adotar o critério da norma mais favorável à vítima. Sobre esse posicionamento, Celso D. de Albuquerque Mello mostra-se mais categórico do que ela: "Considero esta posição (a de Piovesan) já como um grande avanço. Contudo, sou ainda mais radical no sentido de que a norma internacional prevalece sobre a norma constitucional, mesmo naquele caso em que uma norma constitucional posterior tente revogar uma norma internacional constitucionalizada. A nossa 
posição é a que está consagrada na jurisprudência e tratado internacional europeu de que se deve aplicar a norma mais benéfica ao ser humano, seja ela interna ou internacional" (Mello, 1996, p. 25).

Retornando à Piovesan, a autora conclui que, em função da natureza constitucional dos direitos enunciados nos tratados internacionais de proteção dos direitos humanos, podem ocorrer três hipóteses: "a- reproduzir direito assegurado pela Constituição; b- inovar o universo de direitos constitucionalmente previstos; c- contrariar preceito constitucional" (PIOVESAN, 1996, p. 127). Sobre cada uma das proposiçôes, tece respectivamente as seguintes considerações: na primeira, os tratados de direitos humanos reforçarão o valor jurídico de direitos constitucionalmente garantidos; na segunda, os tratados vão ampliar o elenco dos direitos constitucionais, complementando e integrando a declaração constitucional de direitos e, na terceira, a norma mais favorável à proteção da vítima será a prevalecente (PIOVESAN, 1996, p. 127).

Como observação final e para mostrar como pensam os que defendem o entendimento contrário, ou seja, a necessidade de lei ordinária para que tratado ou convenção sobre direitos humanos ingresse no ordenamento jurídico interno, é perceptível a resistência de alguns anos atrás do Judiciário brasileiro. Resistência porque, mesmo em matéria de direitos humanos, havia ainda posições, como a do juiz Pedro Gagliardi, então Presidente do Tribunal de Alçada Criminal do Estado de São Paulo, que, em artigo para a Revista da Escola de Magistratura do Estado do Rio de Janeiro, afirmou: "O respeito aos direitos humanos, segundo a Convenção (Convenção Americana sobre Direitos Humanos-Pacto de São José da Costa Rica), não exclui a aplicação do direito positivo interno. A Constituição Federal, ratificado e promulgado o Tratado, exige a adaptação das normas ao nosso direito interno, inexistindo aplicação automática daquele. A Constituição é a 'suprema lei da terra', não os tratados, que só vigorarão quando da adaptação ao nosso direito positivo interno” (GAGLIARDI, 1998, p. 75).

\section{CONCLUSĀO}

No Brasil, a maioria da doutrina defende a tese monista do conflito de fontes tanto em matéria de Direito da Integração quanto de direitos humanos; já a jurisprudência do STF vem sendo marcada pelo monismo moderado desde 1977.

Particularmente sobre o Direito da Integração e o MERCOSUL, estão se consolidando teses, como a de Paulo Borba Casella, que postulam a necessidade de revisão do Texto Constitucional, para que o processo de integração se efetive na prática, visto que os tribunais brasileiros defendem, em verdade, a necessidade de um ato do Executivo para se poder incorporar a norma estrangeira e, a partir daí, 
igualar o tratado internacional e a lei ordinária, podendo aquele ser modificado posteriormente por esta última.

E existem, ainda, aqueles que, como o argentino Carlos Santiago Nino, abandonaram o formalismo do debate doutrinário e jurisprudencial para fundamentar suas idéias sobre o conflito de fontes no discurso moral.

A nosso ver, uma revisão constitucional, como a advogada por Casella, que ocorreria por meio de emenda, não seria apropriada, já que o Título I da Constituição Federal, que trata dos Princípios Fundamentais, não pode se submeter a qualquer modificação por parte do constituinte derivado. Isso porque esses princípios conferem estrutura a todos os sub-princípios e normas constitucionais que compóem o Texto; por exemplo, aqueles relacionados com os direitos e garantias fundamentais, a organização do Estado e o pluralismo político.

A solução residiria em uma interpretação evolutiva da Carta de 1988 e, sem dúvida, esse seria um trabalho a ser empreendido pelos tribunais. $\mathrm{Na}$ linha de Nino, os juízes deveriam recorrer a princípios básicos e a outros fundamentos supraconstitucionais e compreender que realizam uns em relação aos outros um trabalho coletivo e contínuo de construção do Direito. Deveriam, ainda, tomar decisões com base na Constituição histórica. Em outras palavras, os juízes deveriam se valer não só de fundamentos morais, mas também da interpretação dos próprios princípios básicos que operam ao longo da história do país.

Em suma, particularmente no tocante ao processo de integração, a solução poderia advir do apelo a princípios básicos, morais e até supraconstitucionais que informam o Título I da Carta de 1988, acrescida de uma interpretação e aplicação evolutiva de seu sistema de normas e de uma permanente construção de seu conteúdo através da jurisprudência dos tribunais.

\section{Bibliografia}

Anzilotti, Dionisio (1955): Scritti di diritto internazionale pubblico (Padova, CEDAM, vol. I).

Barroso, Luís Roberto (2003): Interpretação e Aplicação da Constituição. Fundamentos de uma Dogmática Constitucional Transformadora (São Paulo, Saraiva).

Casella, Paulo Borba (1994): A Integração Econômica e seu Tratamento Constitucional. Mercosul: Desafios a Vencer (São Paulo, Conselho Brasileiro de Relações Internacionais).

Castro, Amílcar de (1956): Direito Internacional Privado (Rio de Janeiro, Forense).

Errázuriz Mackenna, Carlos José (1986): La teoría pura del Derecho de Kelsen. Visión crítica (Pamplona, EUNSA). 
Gagliardi, Pedro Luiz Ricardo (1998): "O Poder Judiciário e os Direitos Humanos”, en Revista da EMERJ (N 4) pp. 70-78.

Kelsen, Hans (1953): "Théorie du droit international public", en Recueil des cours. Académie de droit international de la Haye (Nº 84, III) (Leyden, A. W. Sijthoff), pp. 1-203.

Mello, Celso D. de Albuquerque (1986): Curso de Direito Internacional Público (Rio de Janeiro, Freitas Bastos, vol. I).

(1996): Direito Internacional da Integração (Rio de Janeiro, Renovar). (1999): “O $₫ 2^{\circ}$ do art. $5^{\circ}$ da Constituição Federal”, en Torres, Ricardo Lobo (org.). Teoria dos Direitos Fundamentais (Rio de Janeiro, Renovar) pp. $1-33$.

(2000): Direito Constitucional Internacional (Rio de Janeiro, Renovar).

Nino, Carlos Santiago (1997): La constitución de la democracia deliberativa (Barcelona, Gedisa Editorial).

Piovesan, Flávia (1996): Direitos Humanos e o Direito Constitucional Internacional (São Paulo, Max Limonad).

RodAS, João Grandino (1992): "Tratados Internacionais. Sua Executoriedade no Direito Interno Brasileiro", en Revista do Curso de Direito da Universidade Federal de Uberlândia ( $\left.{ }^{\circ} 21\right)$ pp. 311-323.

Tenório, Oscar (1976): Direito Internacional Privado (Rio de Janeiro, Freitas Bastos, vol. III).

Triepel, Heinrich (1899): Völkerrecht und Landesrecht (Leipzig, Hirschfeldt).

VAlladāo, Haroldo (1974): Direito Internacional Privado (Rio de Janeiro, Freitas Bastos, vol. III). 